\title{
The role of dietary protein intake in the prevention of sarcopenia of aging
}

\author{
Jeannette M Beasley, James M. Shikany, and Cynthia A. Thomson
}

\begin{abstract}
Sarcopenia is defined as age-related decrease in muscle mass and performance. Several consensus definitions of sarcopenia exist, each providing different cut points and methodologies for assessing muscle mass and muscle strength. Thus, wide variation in the prevalence of sarcopenia has been reported, generally ranging up to $45 \%$ for men and $26 \%$ for women. Risk factors for sarcopenia include age, malnutrition, and physical inactivity. Additional evidence suggests a protective role for protein supplementation in older adults in order to preserve lean body mass and prevent frailty, accepted intervention targets for reducing the risk of sarcopenia. Protein supplements vary widely in their composition, and small trials of heterogeneous study designs have made it difficult to extrapolate findings to develop data-driven, evidence-based recommendations for protein supplementation in sarcopenia prevention. Short-term randomized, controlled trials of muscle protein synthesis have demonstrated that whey protein increases synthesis more so than casein or soy isolates. Studies also suggest that essential amino acids stimulate muscle protein synthesis to a greater extent than non-essential amino acids. This review summarizes the epidemiological and clinical trial evidence establishing the current definitions for sarcopenia and provides an overview of the state of the evidence for protein supplementation to prevent and/or mitigate sarcopenia.
\end{abstract}

\section{Keywords}

Sarcopenia; diet; protein; amino acids; aging

\section{Introduction}

The U.S. population is rapidly aging, with 2010 US Census Bureau estimates indicating 40.3 million Americans are now 65 years or older. ${ }^{1}$ Between 2000 and 2010, the population 65 years and older grew 15.1 percent, while the total U.S. population grew 9.7 percent. $^{2}$ With age comes a recognized increase in health care utilization that correlates with increasing clinical diagnoses. One commonly recognized clinical indicator of health status in aging adults is functional status, which has been associated with sarcopenia or loss of muscle mass and/or function. ${ }^{3,4}$

Sarcopenia is derived from the Greek roots of "sarx" for flesh and "penia" for lack. Though it can be simply defined as an age-related decrease in muscle mass and performance, establishing criteria to assess sarcopenia in research and clinical practice remains elusive (Table 1). ${ }^{5,6}$ Definitions of sarcopenia used in research commonly rely on gender-specific cut-off points based on the underlying reference population, and as such numerous definitions have been proposed depending on the sample population evaluated. A recent analysis demonstrated the variance in prevalence of sarcopenia using a single population

Corresponding Author: Jeannette M. Beasley, PhD, MPH, RD, Assistant Professor, Department of Epidemiology and Population Health, Albert Einstein College of Medicine, 1300 Morris Park Ave, Belfer 1312 C, Bronx, NY 10461, 718-430-3089 (phone), 718-430-3076 (fax). 
sample ( $\mathrm{n}=674$ middle-aged males and females from the Netherlands), and applying seven different published definitions. ${ }^{7}$ All definitions integrated measures of muscle strength from handgrip dynamometry in addition to muscle mass as estimated by bioelectrical impedance analysis (BIA). Applying seven published definitions and cut-points, the findings indicated a variance in prevalence estimates for sarcopenia ranging from $0-45.2 \%$ in men and $0 \%-25.8 \%$ in women. ${ }^{7}$ The high variance was thought to be partially attributable to the inclusion of a definition and related cut-points that had been derived from a Korean reference population, measures that are markedly different in distribution of muscle strength and mass measures as compared to the U.S. sample.

Despite the propensity for studies to set relevant cut-points for the individual study, at least three consensus definitions of sarcopenia have been developed in order to bring some standardization to the definition of sarcopenia. However, even these three consensus definitions provide different cut points and methodologies for assessing muscle mass and muscle strength. $., 5,8$ Two of the definitions rely on dual-energy x-ray absorptiometry (DXA), which likely would not be suitable as a screening tool in clinical practice due to issues of repeat radiation exposure, practicality, and expense. In contrast, the European Working Group on Sarcopenia in Older People (EWGSOP) established criteria based on BIA, a more available and acceptable, yet less precise measurement of muscle mass in combination with assessment of handgrip strength as an indicator of muscle strength (Table 2). ${ }^{5}$

Sarcopenic obesity is defined as "reduced lean mass with excess fat as a percentage of body weight" (Table 1). ${ }^{9}$ To adequately diagnose sarcopenic obesity requires impedance or DXA measurements of lean and fat mass, although no referent value for lean or lean-to-fat ratio has been established ${ }^{10}$. Sarcopenia is also thought to be characterized by fat infiltration of muscle tissue leading to reduced function. Not all obese individuals demonstrate sarcopenic obesity, and muscle quality likely differentiates individuals with metabolic abnormalities from those without ${ }^{11}$.

Similar to sarcopenia, estimated prevalence of sarcopenic obesity varies widely depending on how the definition is operationalized. When eight definitions were applied to data on muscle strength and mass within the National Health and Nutrition Examination Survey (NHANES) III sample, prevalence estimates of sarcopenic obesity ranged from $4.4 \%$ to $84.0 \%$ in men and from $3.6 \%$ to $94.0 \%$ in women. ${ }^{12}$ A recent review of the literature examining associations between sarcopenic obesity and health indicators suggested inconsistent associations with measures of functional capacity, with more consistent associations with metabolic and cardiovascular disease risk factors ${ }^{13}$. Current literature is limited primarily to cross-sectional analyses and there is large heterogeneity in evaluating these relationships driven largely by variance in the applied definitions of sarcopenic obesity.

\section{Pathophysiology and Risk Factors}

The pathophysiology of sarcopenia is complex (Figure 1). Select contributory factors are not modifiable, including the aging process resulting in reduced sex hormones and mitochondrial dysfunction. Additionally, some will experience neurodegenerative disease with aging that will have detrimental effects in terms of muscle signaling and function. Increases in fat mass may contribute to the loss of muscle mass that ultimately leads to sarcopenic obesity through increased inflammation and upregulation of protein degradation via the ubiquitin-proteasome pathway ${ }^{14}$. Although multiple biological response pathways can contribute to muscle wasting, an increase in corticosteroids and cytokines often occurs. Presence of these inflammatory factors may have detrimental effects on amino acid 
utilization and/or insulin signaling pathways involved in the stimulation of muscle synthesis following food intake. ${ }^{15}$ Sarcopenia, therefore, is not a natural fact of aging, but has an underlying pathophysiology that needs to be better understood. Though the epidemiology of sarcopenia is highly dependent on the definition applied, by most definitions, sarcopenia occurs in similar proportions of men and women, and the prevalence is higher among individuals aged 70 and over ${ }^{12}$. Sarcopenia is also not associated with malnutrition although individuals can present with both diagnoses simultaneously. Importantly, modifiable factors including diet and physical activity, hold promise for reducing inflammation and insulin resistance in aging individuals. ${ }^{6}$

Diet and physical activity are among the most consistently evaluated risk factors for sarcopenia and are commonly targeted in intervention trials to reduce sarcopenia incidence and/or severity. Data are not yet available to estimate the likelihood that sarcopenia can be reversed, but existing literature is suggestive of a role for both physical activity and diet to prevent and/or arrest sarcopenia ${ }^{6}$. Whether these interventions will have efficacy in advanced age is unclear and likely will depend on the functional phenotype of the individual ${ }^{16}$. Yet, many interventions to prevent, reduce or reverse skeletal muscle mass loss associated with age-related sarcopenia integrate multiple modalities, ${ }^{17}$ and as such can be overly burdensome (e.g. strength training) particularly in those of advanced age who may have significant restrictions in mobility. This has led several investigators to evaluate the role of diet, and specifically dietary protein, in reducing sarcopenia risk and progression independent of physical activity.

\section{Dietary Protein and Sarcopenia}

Current protein recommendations set by the Institute of Medicine (IOM) encompass a wide range (10-35\% of energy) and are considered to be somewhat arbitrary as they were largely driven by the difference in energy needs after estimating requirements for carbohydrate and fat needs, reflecting the lack of attention to true protein requirements for health promotion. ${ }^{18}$ The median protein intake in the United States is approximately 15\% of energy, varying little by age and gender during adulthood. ${ }^{19,20}$ This is well below the upper limit set by the IOM of 35\% of energy from protein, but exceeds the Recommended Dietary Allowance (RDA) of $0.8 \mathrm{~g} / \mathrm{kg} / \mathrm{d}$ of protein (i.e., $56 \mathrm{~g}$ of protein/d for a $70-\mathrm{kg}$ person, or $11 \%$ of total energy assuming a 2000-kcal/d diet) and the Estimated Average Requirement (EAR) of 0.66 $\mathrm{g} / \mathrm{kg} / \mathrm{d}$. The RDA estimated requirement is considered to be a minimal requirement based on avoidance of negative nitrogen balance studies conducted primarily in healthy young men. ${ }^{21}$ Therefore, the amount of daily protein necessary to prevent functional decline, particularly with aging, was not considered in developing these recommendations. Importantly, studies of nitrogen balance are widely recognized as an insensitive tool for defining protein requirements, and they do not constitute a clinically relevant endpoint. ${ }^{22}$ It is also unclear whether it is appropriate to generalize protein requirements developed based on healthy young men to a) women and b) older adults. According to data from NHANES 2005-2006, $24 \%$ of women and $12 \%$ of men $>70$ years old consume inadequate protein, as defined by $<0.66 \mathrm{~g} / \mathrm{kg} /$ actual body weight per day. ${ }^{20}$

Emerging evidence suggests dietary protein supplementation above the RDA (i.e., 1-1.5 g/ $\mathrm{kg} / \mathrm{d}$, Table 3) may be an intervention target to prevent and/or mitigate sarcopenia. ${ }^{23,24}$ Dietary protein was inversely associated with loss of lean mass in a sample of older, community-dwelling men and women in the Heath, Aging, and Body Composition study. ${ }^{25}$ Likewise, postmenopausal women in the highest quintile of protein intake had a $32 \%$ lower risk of frailty in the Women's Health Initiative. ${ }^{26}$ Dietary interventions targeting protein intake above the current RDA are a viable approach to treating sarcopenia in that moderate 
increases in protein intake above the RDA have been suggested to reduce the progressive loss of muscle mass with aging. ${ }^{27,28}$

The role of protein supplementation in reducing the risk or arresting sarcopenia of aging is somewhat controversial. Evidence from small, highly controlled clinical trials suggests 2530 grams of high quality protein (including approximately 10 grams of essential amino acids) is necessary to maximally stimulate skeletal muscle protein synthesis ${ }^{29}$. Therefore, testing whether consumption of 25-30 grams of high-quality protein at each meal maintains muscle mass in the elderly warrants further investigation ${ }^{23}$. While beyond the scope of this review, there is also scientific support for physical activity, and in particular resistance training/exercises, as a therapeutic intervention for sarcopenia ${ }^{16}$.

In a group of severely malnourished subjects protein deposition and a gain in fat free (lean/ muscle) mass were found after 10 days of protein-energy supplementation. ${ }^{22}$ Furthermore, two longer-term (24-week) randomized controlled trials among elderly, frail men demonstrated positive effects of a milk-based protein supplement on physical performance measures when consumed alone and lean body mass when consumed along with a strength training regimen. ${ }^{30,31}$

A systematic review of evidence for the effectiveness of energy and protein supplementation on mortality, complications (i.e. pressure sores, deep vein thrombosis, infections), and functional status (i.e. muscle function, cognitive function, mobility) included 62 trials with 10,187 randomized participants aged 65 and older. ${ }^{32}$ Though there was no significant reduction in mortality in the energy and protein supplemented compared with control groups (relative risk (RR) $0.92,95 \%$ confidence interval (CI) 0.81 to 1.04 ) ( $n=42$ trials), mortality results were statistically significant when limited to trials in which participants $(\mathrm{N}=2,461$ from 25 studies) were defined as undernourished (RR $0.79,95 \%$ CI 0.64 to 0.97 ). The risk of complications was reduced in the 24 trials reporting these measures (RR $0.86,95 \% \mathrm{CI}$ 0.75 to 0.99$)$. There was little evidence of benefit in relation to functional status from supplementation, and the measures were too heterogeneous to allow for pooling. The maximum duration for any one trial was 18 months, and longer-term trials may be needed to observe significant changes in parameters such as handgrip strength. As suggested by evidence summarized in Table 4, interventions including an isocaloric comparison arm demonstrated benefits of protein supplementation on muscle mass, strength, and/or physical performance.

One factor thought to contribute to the variance in response to protein supplementation across intervention trials is the formulations of various protein products. Figure 2 illustrates the amino acid content of several protein supplements used in clinical practice including milk-based, whey protein isolate, and various combinations of essential amino acid supplements (Figure 2). Several of these products demonstrated effectiveness in randomized, controlled trials..$^{31,33,34}$ Interventions that provide targeted amino acid/ protein composition to enhance musculogenesis hold potential for even greater gains. ${ }^{35} \mathrm{By}$ definition, essential amino acids cannot be synthesized by the body and are necessary dietary components. A small study comparing a supplement containing only essential amino acids to a supplement having a balance of essential and non-essential amino acids in a sample of 18 suggested essential amino acids are primarily responsible for the amino acidinduced stimulation of muscle protein synthesis. ${ }^{36}$ Randomized controlled trials have been conducted in Italy testing the effectiveness of Aminotrofic ${ }^{\circledR}$, a supplement comprised of essential amino acids. Researchers reported a dose of 4 grams of this supplement administered twice a day between meals resulted in significant increases in grip strength in older adults, ${ }^{37,38}$, and significant increases in lean body mass among sarcopenic individuals. ${ }^{39}$ 
The branched chain essential amino acid leucine, in particular, has been extensively studied due to its anti-catabolic properties and its roles in protein metabolism, glucose homeostasis, insulin action, and recovery from exercise. ${ }^{40}$ The effects of a metabolite of leucine, betahydroxy-beta-methylbutyrate (HMB), on body composition, strength, and physical function measures have been studied in populations of various ages and fitness levels. A 2003 metaanalysis of nine HMB trials with an average sample size of 28 participants, a mean age of 29 years, and duration of 5 weeks reported increases in net lean mass of $0.28 \%$ per week and strength gains of $1.4 \%$ per week. ${ }^{41}$ More recent reviews of HMB included older participants, but sample sizes were still small and the duration of the trials was very short, making it difficult to draw inferences about the long-term effects of supplementation ${ }^{40,42}$. A yearlong, double-blind, randomized, controlled trial enrolling 95 men and women aged 65 years and over reported that supplementation with HMB with L-arginine and L-lysine increased body cell mass by $1.6 \%(\mathrm{P}=0.002)$ and lean mass by $1.2 \%(\mathrm{P}=0.05)^{43}$. A recent review summarizing 17 trials enrolling 1287 participants concluded protein supplementation improves muscle strength and may improve muscle function, as measured by walking speed, handgrip strength, leg strength, balance, and climbing stairs ${ }^{6}$. Despite this evidence, a recent review of diet interventions targeted at mitigating sarcopenia of aging suggested that there remains insufficient study of dietary interventions in healthy aging adults to establish protein recommendations for supplementation ${ }^{24}$. No data are available specific to obese or minority aging women. Ultimately, if data were to consistently suggest that protein supplementation were associated with clinically relevant improvements in muscle strength and muscle function in aging adults, the health status and quality of life in this vulnerable segment of the population could be markedly improved. Additional evidence from high-quality, multicenter clinical trials will be needed to assess the long term effectiveness of increasing essential amino acid intake on improving health outcomes among older adults before more specific recommendations can be disseminated.

Available data suggest clinicians should consider the following when working with patients in which they suspect a diagnosis of sarcopenia:

- With medical approval, perform a body composition assessment of lean and fat mass; evaluate against currently available cut-points and definitions.

- Evaluate patient's physical activity - frequency, type (especially resistance exercise), intensity as well as sedentary time, and any limitations in ambulation. Refer to a physical therapist and/or exercise physiologist as indicated.

- Evaluate protein intake including amino acid profile and tailor dietary recommendations to assure intake is meeting DRI for daily protein, with consideration for individual health status (i.e. renal disease, diabetes, etc.).

Consider protein supplementation in patients with sarcopenia who are unsuccessful meeting protein needs through diet modifications alone and there are no medical contraindications.

\section{Acknowledgments}

Funding Acknowledgment

This work was supported by the National Institute of Aging [R00AG035002].

\section{References}

1. U.S. Census Bureau. Washington, DC: 2011. Statistical Abstract of the United States: 2012 (131st Edition). <http://www.census.gov/compendia/statab/>.

2. Werner, CA. Commerce UDo. , editor. The Older Population: 2010; 2010 Census Briefs: US Census Bureau. 2011. p. 1-19. 
3. Evans WJ. Skeletal muscle loss: cachexia, sarcopenia, and inactivity. Am J Clin Nutr. 2010; 91:1123S-1127S. [PubMed: 20164314]

4. Fielding RA, Vellas B, Evans WJ, et al. Sarcopenia: an undiagnosed condition in older adults. Current consensus definition: prevalence, etiology, and consequences. International working group on sarcopenia. Journal of the American Medical Directors Association. 2011; 12:249-256. [PubMed: 21527165]

5. Cruz-Jentoft AJ, Baeyens JP, Bauer JM, et al. Sarcopenia: European consensus on definition and diagnosis: Report of the European Working Group on Sarcopenia in Older People. Age Ageing. 2010; 39:412-423. [PubMed: 20392703]

6. Malafarina V, Uriz-Otano F, Iniesta R, Gil-Guerrero L. Effectiveness of nutritional supplementation on muscle mass in treatment of sarcopenia in old age: a systematic review. Journal of the American Medical Directors Association. 2013; 14:10-17. [PubMed: 22980996]

7. Bijlsma AY, Meskers CG, Ling CH, et al. Defining sarcopenia: the impact of different diagnostic criteria on the prevalence of sarcopenia in a large middle aged cohort. Age. 2013; 35:871-881. [PubMed: 22314402]

8. Muscaritoli M, Anker SD, Argiles J, et al. Consensus definition of sarcopenia, cachexia and precachexia: joint document elaborated by Special Interest Groups (SIG) "cachexia-anorexia in chronic wasting diseases" and "nutrition in geriatrics". Clin Nutr. 2010; 29:154-159. [PubMed: 20060626]

9. Heber D, Ingles S, Ashley JM, Maxwell MH, Lyons RF, Elashoff RM. Clinical detection of sarcopenic obesity by bioelectrical impedance analysis. Am J Clin Nutr. 1996; 64:472S-477S. [PubMed: 8780366]

10. Zamboni M, Mazzali G, Fantin F, Rossi A, Di Francesco V. Sarcopenic obesity: a new category of obesity in the elderly. Nutrition, metabolism, and cardiovascular diseases : NMCD. 2008; 18:388395.

11. Barbat-Artigas S, Filion ME, Plouffe S, Aubertin-Leheudre M. Muscle quality as a potential explanation of the metabolically healthy but obese and sarcopenic obese paradoxes. Metabolic syndrome and related disorders. 2012; 10:117-122. [PubMed: 22182254]

12. Batsis JA, Barre LK, Mackenzie TA, Pratt SI, Lopez-Jimenez F, Bartels SJ. Variation in the Prevalence of Sarcopenia and Sarcopenic Obesity in Older Adults Associated with Different Research Definitions: Dual-Energy X-Ray Absorptiometry Data from the National Health and Nutrition Examination Survey 1999-2004. J Am Geriatr Soc. 2013

13. Prado CM, Wells JC, Smith SR, Stephan BC, Siervo M. Sarcopenic obesity: A Critical appraisal of the current evidence. Clin Nutr. 2012; 31:583-601. [PubMed: 22809635]

14. Waters DL, Baumgartner RN. Sarcopenia and obesity. Clin Geriatr Med. 2011; 27:401-421. [PubMed: 21824555]

15. Dardevet D, Remond D, Peyron MA, Papet I, Savary-Auzeloux I, Mosoni L. Muscle wasting and resistance of muscle anabolism: the "anabolic threshold concept" for adapted nutritional strategies during sarcopenia. The Scientific World Journal. 2012; 2012:269531.

16. Barillaro C, Liperoti R, Martone AM, Onder G, Landi F. The new metabolic treatments for sarcopenia. Aging clinical and experimental research. 2013; 25:119-127. [PubMed: 23739896]

17. Breen L, Phillips SM. Skeletal muscle protein metabolism in the elderly: Interventions to counteract the 'anabolic resistance' of ageing. Nutr Metab. 2011; 8:68.

18. Dietary Reference Intakes for Energy, Carbohydrate, Fiber, Fat, Fatty Acids, Cholesterol, Protein, and Amino Acids (Macronutrients). Washington, D.C.: National Academies Press; 2002.

19. Fulgoni VL 3rd. Current protein intake in America: analysis of the National Health and Nutrition Examination Survey, 2003-2004. Am J Clin Nutr. 2008; 87:1554S-1557S. [PubMed: 18469286]

20. Berner LA, Becker G, Wise M, Doi J. Characterization of Dietary Protein among Older Adults in the United States: Amount, Animal Sources, and Meal Patterns. Journal of the Academy of Nutrition and Dietetics. 2013; 113:809-815. [PubMed: 23491327]

21. Rand WM, Pellett PL, Young VR. Meta-analysis of nitrogen balance studies for estimating protein requirements in healthy adults. Am J Clin Nutr. 2003; 77:109-127. [PubMed: 12499330]

22. World Health Organization. Report: WHO Press; 2007. Protein and amino acid requirements in human nutrition: report of a FAO/WHO/UNU consultation. Report No.: 935 
23. Volpi E, Campbell WW, Dwyer JT, et al. Is the optimal level of protein intake for older adults greater than the recommended dietary allowance? J Gerontol A Biol Sci Med Sci. 2013; 68:677681. [PubMed: 23183903]

24. Morley JE, Argiles JM, Evans WJ, et al. Nutritional recommendations for the management of sarcopenia. Journal of the American Medical Directors Association. 2010; 11:391-396. [PubMed: 20627179]

25. Houston DK, Nicklas BJ, Ding J, et al. Dietary protein intake is associated with lean mass change in older, community-dwelling adults: the Health, Aging, and Body Composition (Health ABC) Study. Am J Clin Nutr. 2008; 87:150-155. [PubMed: 18175749]

26. Beasley JM, LaCroix AZ, Neuhouser ML, et al. Protein intake and incident frailty in the Women's Health Initiative observational study. J Am Geriatr Soc. 2010; 58:1063-1071. [PubMed: 20487071]

27. Campbell WW, Trappe TA, Wolfe RR, Evans WJ. The recommended dietary allowance for protein may not be adequate for older people to maintain skeletal muscle. J Gerontol A Biol Sci Med Sci. 2001; 56:M373-M380. [PubMed: 11382798]

28. Wolfe RR, Miller SL, Miller KB. Optimal protein intake in the elderly. Clinical nutrition (Edinburgh, Scotland). 2008; 27:675-684.

29. Paddon-Jones D, Rasmussen BB. Dietary protein recommendations and the prevention of sarcopenia. Current opinion in clinical nutrition and metabolic care. 2009; 12:86-90. [PubMed: 19057193]

30. Tieland M, Dirks ML, van der Zwaluw N, et al. Protein supplementation increases muscle mass gain during prolonged resistance-type exercise training in frail elderly people: a randomized, double-blind, placebo-controlled trial. Journal of the American Medical Directors Association. 2012; 13:713-719. [PubMed: 22770932]

31. Tieland M, van de Rest O, Dirks ML, et al. Protein supplementation improves physical performance in frail elderly people: a randomized, double-blind, placebo-controlled trial. Journal of the American Medical Directors Association. 2012; 13:720-726. [PubMed: 22889730]

32. Milne AC, Potter J, Vivanti A, Avenell A. Protein and energy supplementation in elderly people at risk from malnutrition. Cochrane Database Syst Rev. 2009 CD003288.

33. Dillon EL, Sheffield-Moore M, Paddon-Jones D, et al. Amino acid supplementation increases lean body mass, basal muscle protein synthesis, and insulin-like growth factor-I expression in older women. The Journal of clinical endocrinology and metabolism. 2009; 94:1630-1637. [PubMed: 19208731]

34. Kim HK, Suzuki T, Saito K, et al. Effects of exercise and amino acid supplementation on body composition and physical function in community-dwelling elderly Japanese sarcopenic women: a randomized controlled trial. J Am Geriatr Soc. 2012; 60:16-23. [PubMed: 22142410]

35. Paddon-Jones D. Interplay of stress and physical inactivity on muscle loss: Nutritional countermeasures. The Journal of nutrition. 2006; 136:2123-2126. [PubMed: 16857828]

36. Volpi E, Kobayashi H, Sheffield-Moore M, Mittendorfer B, Wolfe RR. Essential amino acids are primarily responsible for the amino acid stimulation of muscle protein anabolism in healthy elderly adults. The American Journal of Clinical Nutrition. 2003; 78:250-258. [PubMed: 12885705]

37. Rondanelli M, Opizzi A, Antoniello N, et al. Effect of essential amino acid supplementation on quality of life, amino acid profile and strength in institutionalized elderly patients. Clin Nutr. 2011; 30:571-577. [PubMed: 21636183]

38. Scognamiglio R, Piccolotto R, Negut C, Tiengo A, Avogaro A. Oral amino acids in elderly subjects: effect on myocardial function and walking capacity. Gerontology. 2005; 51:302-308. [PubMed: 16110231]

39. Dal Negro RW, Aquilani R, Bertacco S, Boschi F, Micheletto C, Tognella S. Comprehensive effects of supplemented essential amino acids in patients with severe COPD and sarcopenia. Monaldi Arch Chest Dis. 2010; 73:25-33. [PubMed: 20499791]

40. Wilson GJ, Wilson JM, Manninen AH. Effects of beta-hydroxy-beta-methylbutyrate (HMB) on exercise performance and body composition across varying levels of age, sex, and training experience: A review. Nutr Metab. 2008; 5:1. 
41. Nissen SL, Sharp RL. Effect of dietary supplements on lean mass and strength gains with resistance exercise: a meta-analysis. J Appl Physiol. 2003; 94:651-659. [PubMed: 12433852]

42. Zanchi NE, Gerlinger-Romero F, Guimaraes-Ferreira L, et al. HMB supplementation: clinical and athletic performance-related effects and mechanisms of action. Amino Acids. 2011; 40:10151025. [PubMed: 20607321]

43. Baier S, Johannsen D, Abumrad N, Rathmacher JA, Nissen S, Flakoll P. Year-long changes in protein metabolism in elderly men and women supplemented with a nutrition cocktail of betahydroxy-beta-methylbutyrate (HMB), L-arginine, and L-lysine. JPEN J Parenter Enteral Nutr. 2009; 33:71-82. [PubMed: 19164608]

44. Evans WJ, Morley JE, Argiles J, et al. Cachexia: a new definition. Clin Nutr. 2008; 27:793-799. [PubMed: 18718696]

45. Fried LP, Tangen CM, Walston J, et al. Frailty in older adults: evidence for a phenotype. The journals of gerontology Series A, Biological sciences and medical sciences. 2001; 56:M146M156.

46. Janssen I, Baumgartner RN, Ross R, Rosenberg IH, Roubenoff R. Skeletal muscle cutpoints associated with elevated physical disability risk in older men and women. Am J Epidemiol. 2004; 159:413-421. [PubMed: 14769646]

47. Lauretani F, Russo CR, Bandinelli S, et al. Age-associated changes in skeletal muscles and their effect on mobility: an operational diagnosis of sarcopenia. J Appl Physiol. 2003; 95:1851-1860. [PubMed: 14555665]

48. Cesari M, Kritchevsky SB, Penninx BW, et al. Prognostic value of usual gait speed in wellfunctioning older people--results from the Health, Aging and Body Composition Study. J Am Geriatr Soc. 2005; 53:1675-1680. [PubMed: 16181165]

49. Leenders M, Verdijk LB, van der Hoeven L, et al. Prolonged leucine supplementation does not augment muscle mass or affect glycemic control in elderly type 2 diabetic men. J Nutr. 2011; 141:1070-1076. [PubMed: 21525248]

50. Verhoeven S, Vanschoonbeek K, Verdijk LB, et al. Long-term leucine supplementation does not increase muscle mass or strength in healthy elderly men. Am J Clin Nutr. 2009; 89:1468-1475. [PubMed: 19321567]

51. Flakoll P, Sharp R, Baier S, Levenhagen D, Carr C, Nissen S. Effect of beta-hydroxy-betamethylbutyrate, arginine, and lysine supplementation on strength, functionality, body composition, and protein metabolism in elderly women. Nutrition. 2004; 20:445-451. [PubMed: 15105032] 


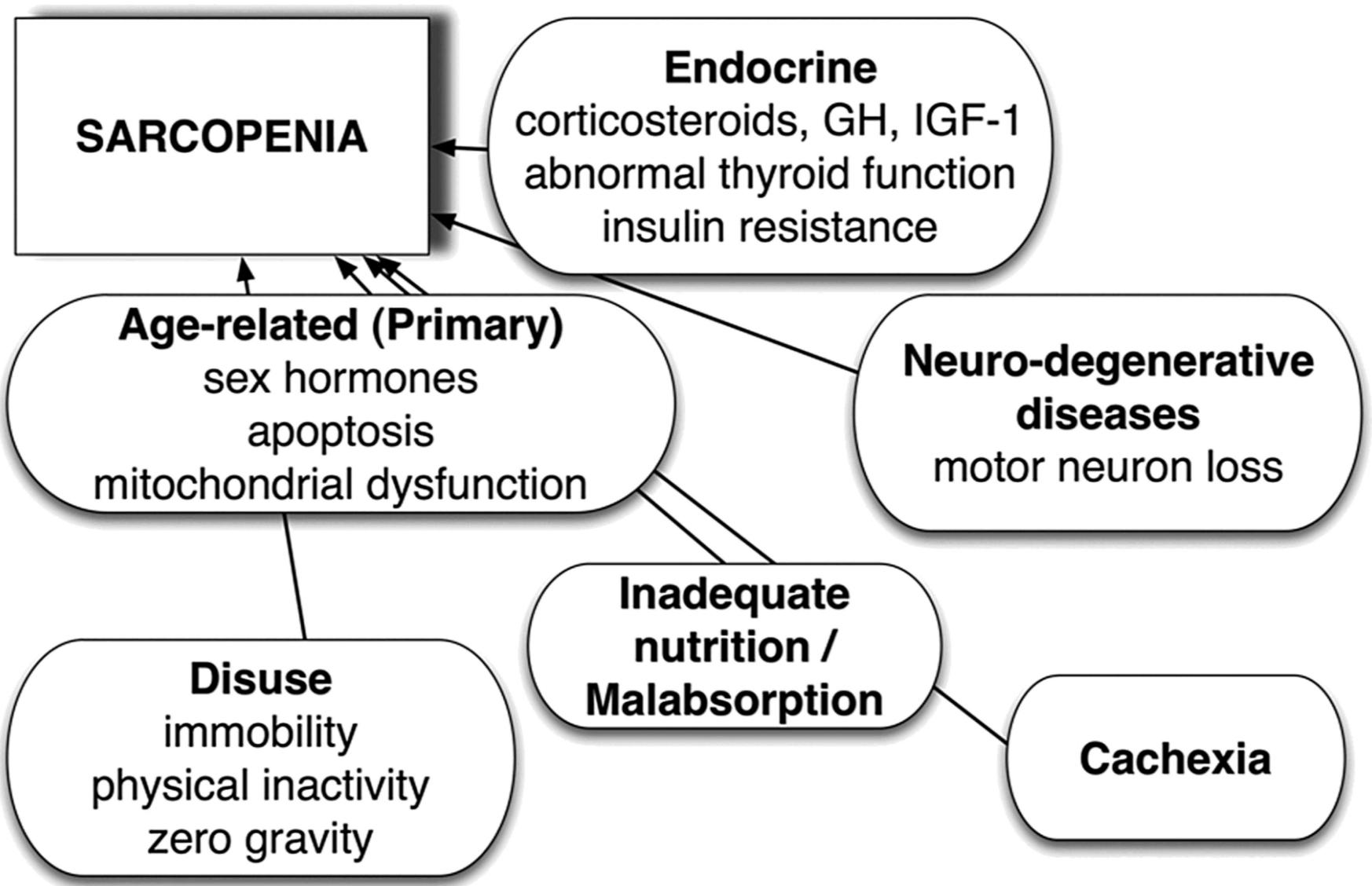

Figure 1.

Pathophysiology of Sarcopenia (from Jentoft-2010 ${ }^{5}$ ) 
Paddon Jones 2006 (Whey)

Paddon Jones 2006 (EAA)

Solerte 2008 (EAA)

Kim et al 2012 (EAA)

Tieland 2012 (Milk)

Figure 2.

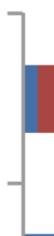

.
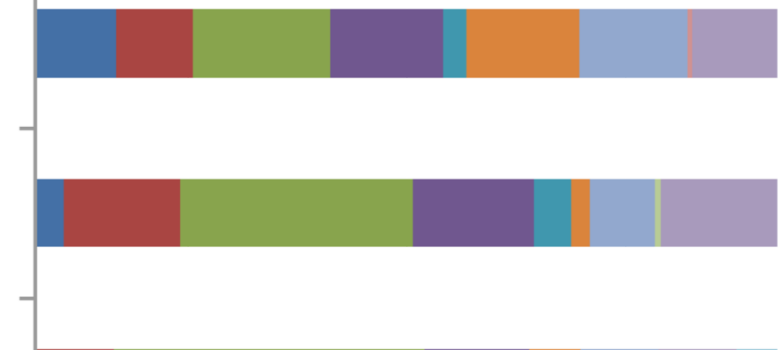

.

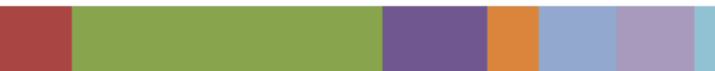

\section{.}

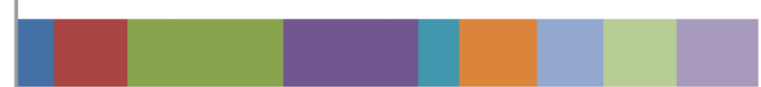

WHO
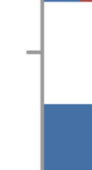
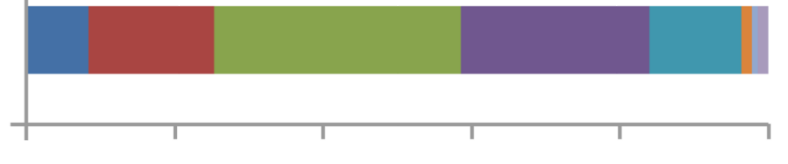

$\begin{array}{llllll}0 \% & 20 \% & 40 \% & 60 \% & 80 \% & 100 \%\end{array}$

His

- lle

Leu

Lys

Met+Cys

Phe

Thr

Trp

Tyr

Val

NEAA

Comparison of Selected Amino Acid Composition of Supplements Demonstrating Positive Effects on Muscle Protein Synthesis and/or Physical Performance

Abbreviations: WHO=World Health Organization; His=histidine; Ile=isoleucine; Leu=leucine; Lys=lysine; Met+Cys = methionine and cysteine; Phe=phenylalanine;

$\mathrm{Thr}=$ threonine; Trp=tryptophan; Tyr=tyrosine; Val=valine; NEAA=non-essential amino acids 
Table 1

Definitions of sarcopenia, cachexia, and frailty

\begin{tabular}{|ll|}
\hline Term & Definition \\
\hline Sarcopenia & $\begin{array}{l}\text { "The age-associated loss of skeletal muscle mass and function. Sarcopenia is a complex syndrome that is associated } \\
\text { with muscle mass loss alone or in conjunction with increased fat mass. The causes of sarcopenia are multifactorial and } \\
\text { can include disuse, changing endocrine function, chronic diseases, inflammation, insulin resistance, and nutritional } \\
\text { deficiencies. While cachexia may be a component of sarcopenia, the two conditions are not the same.". }\end{array}$ \\
\hline Sarcopenic Obesity & "Reduced lean mass with excess fat as a percentage of body weight"9. \\
\hline Cachexia & $\begin{array}{l}\text { "A complex metabolic syndrome associated with underlying illness and characterized by loss of muscle with or without } \\
\text { loss of fat mass. The prominent clinical feature of cachexia is weight loss in adults (corrected for fluid retention) or } \\
\text { growth failure in children (excluding endocrine disorders). Anorexia, inflammation, insulin resistance and increased } \\
\text { muscle protein breakdown are frequently associated with cachexia. Cachexia is distinct from starvation, age-related loss } \\
\text { of muscle mass, primary depression, malabsorption and hyperthyroidism and is associated with increased morbidity."44 }\end{array}$ \\
\hline Frailty & $\begin{array}{l}\text { "A clinical syndrome in which three or more of the following criteria were present: unintentional weight loss (10 lbs in } \\
\text { past year), self-reported exhaustion, weakness (grip strength), slow walking speed, and low physical activity." }\end{array}$ \\
\hline
\end{tabular}




\section{Table 2}

Clinical diagnosis of sarcopenia: current criteria including clinical indices and cut-points for defining sarcopenia in aging adults.

\begin{tabular}{|c|c|c|c|c|}
\hline Construct & $\begin{array}{l}\text { Measurement } \\
\text { approach }\end{array}$ & Cut-points, Men & $\begin{array}{l}\text { Cut-points, } \\
\text { Women }\end{array}$ & $\begin{array}{l}\text { Study } \\
\text { Population }\end{array}$ \\
\hline Muscle mass & Bioelectrical impedance analysis & $\begin{array}{l}\text { Normal muscle: } \geq 10.76 \mathrm{~kg} / \mathrm{m}^{2} \\
\text { Moderate sarcopenia, } 8.51- \\
10.75 \mathrm{~kg} / \mathrm{m}^{2} \text { Severe sarcopenia, } \\
\$ 8.50 \mathrm{~kg} / \mathrm{m}^{2}\end{array}$ & $\begin{array}{l}\text { Normal muscle, } \Varangle 6.76 \mathrm{~kg} / \\
\mathrm{m}^{2} \text { Moderate sarcopenia, } \\
5.76-6.75 \mathrm{~kg} / \mathrm{m}^{2} \text { Severe } \\
\text { sarcopenia, } 5.75 \mathrm{~kg} / \mathrm{m}^{2}\end{array}$ & NHANES III ${ }^{46}$ \\
\hline Muscle strength & Handgrip strength & $<30 \mathrm{~kg}^{*}$ & $<20 \mathrm{~kg}^{*}$ & InCHIANTI $^{47}$ \\
\hline Physical Performance & Gait speed & \multicolumn{2}{|c|}{$<1 \mathrm{~m} / \mathrm{s}$ 6-m course } & Health $\mathrm{ABC}^{48}$ \\
\hline
\end{tabular}

* Among individuals that walk slower than $0.8 \mathrm{~m} / \mathrm{s}$

Adapted from Cruz-Jentoft-2010 5 


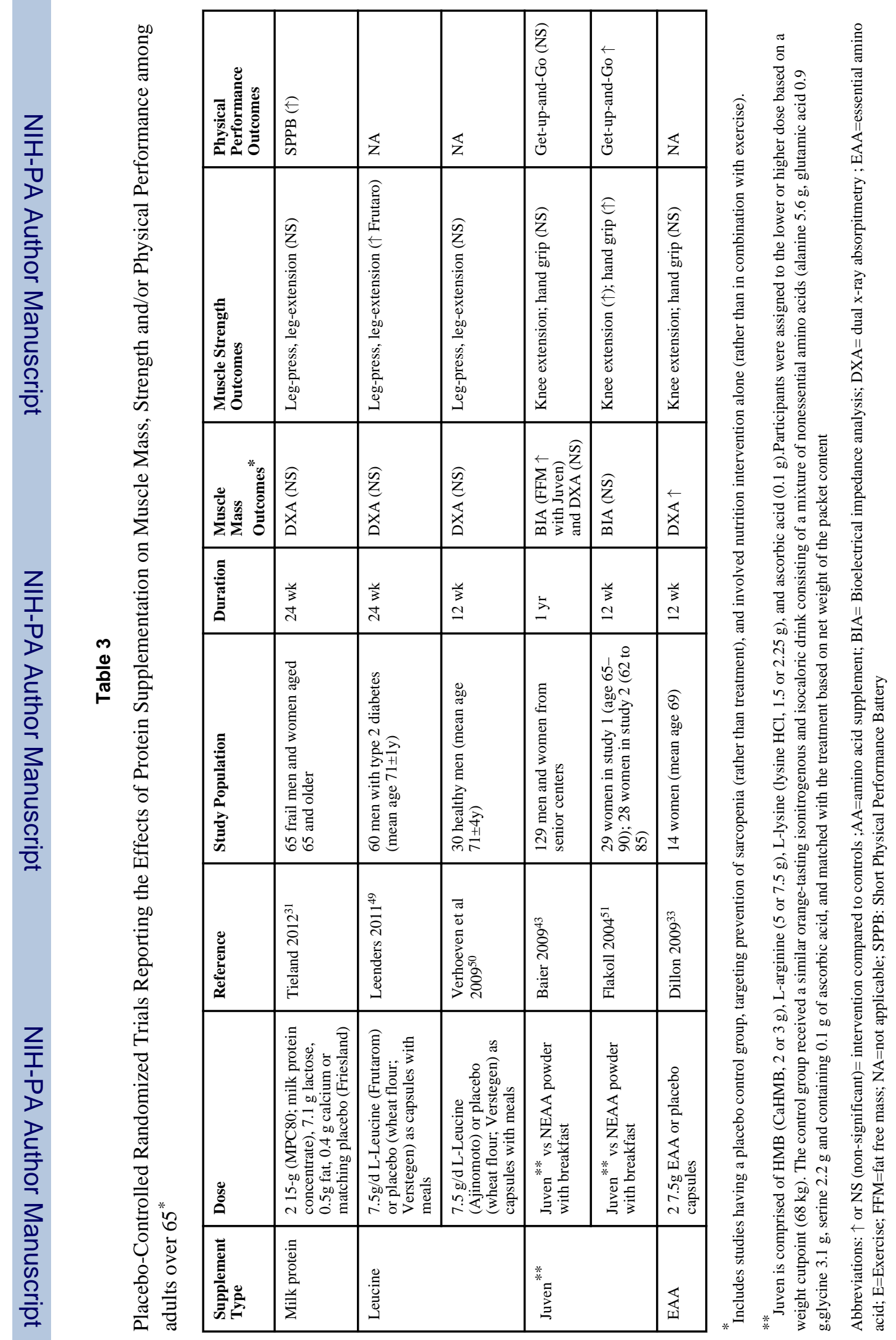

